\title{
Systemic inflammation after inspiratory loading in chronic obstructive pulmonary disease
}

\author{
Antonia Fuster \\ Jaume Sauleda \\ Ernest Sala \\ Bernardí Barceló \\ Jaume Pons ${ }^{2}$ \\ Miguel Carrera \\ Aina Noguera' \\ Bernat Togores \\ Alvar GN Agustí
}

Serveis de Pneumologia, 'Analisis Clinics, and 'Inmunología, Hospital Universitari Son Dureta, Fundación

Caubet-Cimera and CIBER

Enfermedades Respiratorias, Mallorca, Spain
Correspondence: Jaume Sauleda Servei Pneumologia. Hospital Univ. Son Dureta.Andrea Doria 55, 07014 Palma Mallorca, Spain

Tel $+34971 \quad 175433$

Fax +34 97I I75228

Email jsauleda@hsd.es
Objective: Patients with chronic obstructive pulmonary disease (COPD) present systemic inflammation. Strenuous resistive breathing induces systemic inflammation in healthy subjects. We hypothesized that the increased respiratory load that characterizes COPD can contribute to systemic inflammation in these patients.

Patients and methods: To test this hypothesis, we compared leukocyte numbers and levels

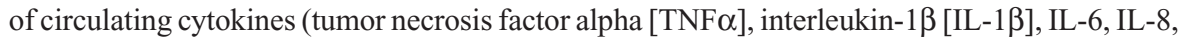
and IL-10), before and 1 hour after maximal incremental inspiratory loading in 13 patients with stable COPD (forced expiratory volume in one second $\left[\mathrm{FEV}_{1}\right] 29 \pm 2.5 \%$ ref) and in 8 healthy sedentary subjects ( $\mathrm{FEV}_{1} 98 \pm 5 \%$ ref).

Results: We found that: (1) at baseline, patients with COPD showed higher leukocyte counts and IL-8 levels than controls ( $p<0.01$ ); and, (2) one hour after maximal inspiratory loading these values were unchanged, except for IL-10, which increased in controls $(p<0.05)$ but not in patients with COPD.

Conclusions: This study confirms the presence of systemic inflammation in COPD, shows that maximal inspiratory loading does not increase the levels of pro-inflammatory cytokines (IL-1 $\beta$, IL-8) in COPD patients or controls, but suggests that the former may be unable to mount an appropriate systemic anti-inflammatory response to exercise.

Keywords: COPD, endurance, exercise, IL-10, respiratory muscles, systemic inflammation

\section{Introduction}

Chronic obstructive pulmonary disease (COPD) is characterized by pulmonary (Pauwels et al 2001) and systemic inflammation (Agusti et al 2001). In healthy subjects, whole body exercise results in increased circulating leukocyte counts (Bury et al 1996), higher plasma concentration of pro-inflammatory cytokines (interleukin-6 [IL-6], interleukin-1 $\beta$ [ IL-1 $\beta$ ], tumor necrosis factor alpha [TNF- $\alpha$ ]) (Smith et al 2000), oxidative stress (Sen 1995), an increased levels of acute phase reactants (C- reactive protein [CRP]) and creatin phosphoquinase (Pizza et al 1995). This occurs also after strenuous resistive breathing (Vassilakopoulos et al 1999, 2004).

Airway resistance and the work of breathing are typically increased in patients with severe COPD, especially during acute exacerbations of the disease (AECOPD) (Barbera et al 1997; Ramirez-Sarmiento et al 2002). Systemic inflammation is known to increase during AECOPD (Malo et al 2002). We hypothesized that the increased respiratory load that characterizes COPD, particularly during AECOPD, can contribute to systemic inflammation in these patients. To test this hypothesis, we designed a prospective and interventional study comparing circulating leukocyte counts and plasma concentration of IL-1 $\beta$, IL-6, TNF $\alpha$, IL-8, and IL-10 in patients with severe COPD and healthy controls, before and after a maximal incremental inspiratory loading test (Martyn et al 1987). 


\section{Methods}

\section{Subjects and ethics}

We studied 13 males with very severe COPD (GOLD IV) (Pauwels et al 2001) and 8 healthy male volunteers. Patients with COPD were consecutively recruited from the outpatient clinic of our department. None of them had required hospital admission or treatment change during the preceding 3 months nor had any other concomitant chronic inflammatory disease. All patients received long-acting $\beta 2$ agonists, inhaled anticholinergics, and inhaled steroids. None of them was receiving oral steroids. We also studied 8 healthy sedentary volunteers who served as controls. All participants gave their written consent after being fully informed of the purpose, characteristics, and nature of the study, which had been approved by the Ethics Review Board of our institution.

\section{Design of the study}

Patients were studied in two different days. The first one, forced spirometry, arterial blood gases and maximal inspiratory and expiratory pressures were determined. Then three to seven days later, subjects performed a maximal inspiratory loading test (MILT). This was always done at the same time of the day (4 pm), at least four hours after the last meal. Briefly, a venous line was inserted into an antecubital vein and a baseline venous blood sample was obtained in EDTA containing tubes. MILT was then performed until exhaustion (see below) and, 1 hour later, a second venous blood sample was obtained. Plasma was separated from whole blood immediately after blood sampling by centrifugation at $2000 \mathrm{rpm}$ for $10 \mathrm{~min}$, and stored frozen at $-80^{\circ} \mathrm{C}$.

\section{Lung function tests}

A forced spirometry (GS, Warren E Collins, Braintree, MA, US) was obtained in all participants according to international guidelines (American Thoracic Society 1995). Spirometric reference values were those of a Mediterranean population (Roca et al 1986). In patients with COPD, an arterial blood sample was obtained by radial artery punction under local anaesthesia. This was immediately assayed for $\mathrm{PaO}_{2}, \mathrm{PaCO}_{2}$, and $\mathrm{pH}$ (IL BG3, Izasa, Spain). This was not obtained in healthy subjects who all had normal arterial oxyhemoglobin saturation by pulse oxymetry (504-US, Criticare systems, Waukesha, WI). Maximum inspiratory pressure (MIP) was measured according to the standard technique (Morales et al 1997) using a differential pressure transducer (Sibelemed, Barcelona, Spain) whose output was digitized and stored into a computer, while the patient was in the sitting position. MIP reference values were from caucasian population (Morales et al 1997).

\section{Maximal incremental inspiratory load test (MILT)}

We followed the methodology described by Martyn and colleagues (1987). In brief, subjects were asked to breath (following a metronome) through a weighted inspiratory plunger (with an orifice whose diameter was $2.1 \mathrm{~cm}$ ) connected to a bidirectional valve, while wearing a nose clip. Initially, there was no weight load, but this was increased every two minutes with $25 \mathrm{~g}$ for COPD patients (or $50 \mathrm{~g}$ for healthy subjects) until subjects could no longer inspire (three unsuccessful attempts to open the inspiratory valve). The expiratory circuit was connected to an $\mathrm{O}_{2}$ and $\mathrm{CO}_{2}$ analyzer (GS, Warren E Collins, Braintree, MA, USA) that allowed breath-by-breath measurements of volume, flow, oxygen consumption $\left(\mathrm{VO}_{2}\right)$, and carbon dioxide production $\left(\mathrm{VCO}_{2}\right)$.

\section{Inflammatory markers}

Total and differential leukocyte counts were determined automatically in whole blood (Sysmex K-4500, Toa Medical Electronics Co Ltd, Kobe, Japan). In plasma, the concentration of IL1 $\beta$, IL-6, TNF $\alpha$, IL-10, and IL-8 was determined using a cytokine bead array system (BD Biosciences San Diego, CA, USA). This assay system consists of a mixture of six types of beads of uniform size that contain different fluorescence intensities of a red-emitting dye. A different capture antibody (Ab) against each cytokine is covalently coupled to each type of bead. Cytokines bound to these Abs are detected by use of Abs labeled with phycoerythrin. The fluorescence intensity measured with phycoerythrin is proportional to the cytokine concentration in the sample and is quantified from a calibration curve. The detection limits of these assays were $7.2 \mathrm{pg} / \mathrm{mL}$ for IL- $1 \beta$, $2.5 \mathrm{pg} / \mathrm{mL}$ for IL-6, $3.7 \mathrm{pg} / \mathrm{mL}$ for TNF- $\alpha, 3.6 \mathrm{pg} / \mathrm{mL}$ for IL-8, and $3.3 \mathrm{pg} / \mathrm{mL}$ for IL-10. All assays were performed in duplicated. Intra-assay variation was $<10 \%$.

\section{Statistical analysis}

Results are shown as mean \pm SEM. The Mann-Whitney test was used to compare results between the two groups of subjects whereas the Wilcoxon test was used to compare data before and after MILT. A $p$ value lower than 0.05 was considered significant. 


\section{Results}

Table 1 shows the main clinical and functional data of subjects studied. Patients with COPD were older than controls and had severe airflow obstruction, mild hypoxemia without hypercapnia and a moderate reduction of MIP (Table 1). By definition, lung function was normal in healthy volunteers.

Table 2 presents the results of MILT. Healthy subjects achieved a higher peak load but the rest of variables were similar in both groups. Of note, $\mathrm{VO}_{2}$ increased significantly with MILT in both groups, indicating significant respiratory muscle activity.

Figure 1 presents the values of different inflammatory markers determined in both groups, before and 1 hour after MILT. At baseline, leukocyte counts (panel A) were higher in patients with COPD $\left(8.3 \pm 0.4 \times 10^{3} / \mathrm{mL}\right)$ than controls $\left(6.2 \pm 0.5 \times 10^{3} / \mathrm{mL}, \mathrm{p}<0.01\right)$; these values were unchanged after MILT, so differences persisted $\left(8.5 \pm 0.3 \times 10^{3} / \mathrm{mL}\right.$ and $6.5 \pm 0.5 \times 10^{3} / \mathrm{mL}$ respectively, $\left.\mathrm{p}<0.01\right)$. IL-8 levels at

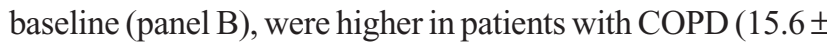
$3 \mathrm{pg} / \mathrm{mL}$ vs $5.9 \pm 0.8 \mathrm{pg} / \mathrm{mL}, \mathrm{p}<0.01)$. MILT did not change these values significantly so differences remained after it $(13.4 \pm 1.8 \mathrm{pg} / \mathrm{mL}$ vs $5.5 \pm 0.4 \mathrm{pg} / \mathrm{mL}$ respectively, $\mathrm{p}<0.01)$. The concentration of IL-1 $\beta$ (panel C) was not different between groups at baseline $(38 \pm 19 \mathrm{pg} / \mathrm{mL}$ vs $25 \pm 8 \mathrm{pg} / \mathrm{mL})$ nor did it change with MILT ( $46 \pm 26 \mathrm{pg} / \mathrm{mL}$ vs $20 \pm 2 \mathrm{pg} / \mathrm{mL})$ (panel C). IL-6 and TNF- $\alpha$ levels were undetectable in almost all subjects. Interestingly, we observed that IL-10 values were similar at baseline but increased after exercise only in healthy subjects $(5.9 \pm 0.8 \mathrm{pg} / \mathrm{mL})$ but not in patients with COPD (3.6 $\pm 0.5 \mathrm{pg} / \mathrm{mL}, \mathrm{p}<0.05)$ (panel D).

\section{Discussion}

This study: (1) confirms the presence of systemic inflammation in patients with severe COPD, as shown by their higher leukocyte counts and increased IL-8 plasma levels; (2) does not support the hypothesis that a high inspiratory load may contribute to systemic inflammation in COPD; and, (3) shows that, at variance with healthy subjects, patients with COPD were unable to mount an appropriate anti-inflammatory response after MILT (as indicated by their low plasma levels of IL-10 after MILT).

It is now well established that systemic inflammation occurs in patients with COPD (Agusti et al 2001). In this study we hypothesized that the increased respiratory load that characterizes COPD may contribute to it. This hypothesis was based upon the following, previously established, observations. First, increased airway resistance is a key physiological abnormality in COPD (Hogg 2004). Second, leukocytosis,
Table I Clinical and lung function data

\begin{tabular}{lll}
\hline & COPD patients & Healthy subjects \\
\hline Age $(\mathrm{yrs})$ & $63 \pm 2^{* *}$ & $46 \pm \mathrm{I}$ \\
$\mathrm{BMI}\left(\mathrm{Kg} / \mathrm{m}^{2}\right)$ & $24.7 \pm \mathrm{I} . \mathrm{I}$ & $26.5 \pm 0.6$ \\
Smoking history (pack-yr) & $62 \pm 6^{* *}$ & $2.5 \pm 2$ \\
$\mathrm{FEV}_{1}(\%$ reference) & $29 \pm 2.5^{* *}$ & $98 \pm 5$ \\
$\mathrm{FEV}_{1} / \mathrm{FVC}(\%)$ & $37 \pm 2^{* *}$ & $73 \pm 2$ \\
$\mathrm{PaO}_{2}(\mathrm{mmHg})$ & $70 \pm 3.3$ & $\mathrm{NA}$ \\
$\mathrm{PaCO}_{2}(\mathrm{mmHg})$ & $42 \pm 2.3$ & $\mathrm{NA}$ \\
$\mathrm{SaO}_{2} \%$ & $95 \pm 3^{*}$ & $97 \pm 0.4$ \\
$\mathrm{MIP}^{*} \%$ reference) & $68 \pm 6^{* *}$ & $96 \pm 8$ \\
\hline
\end{tabular}

Abbreviations: BMI, body mass index; FEV , forced expiratory volume in I second; $\mathrm{FVC}$, forced vital capacity; $\mathrm{PaO}_{2}$, arterial partial pressure of oxygen; $\mathrm{PaCO}_{2}$, arterial partial pressure of carbon dioxide; MIP, maximal inspiratory pressure; NA, not available.

${ }^{* *} \mathrm{p}<0.01$

increased circulating levels of pro-inflammatory cytokines (IL-6, IL-8, IL-1 $\beta$, TNF $\alpha$ ) and oxidative stress have been reported in response to intense whole body exercise in athletes and healthy subjects (Rohde et al 1997; Smith et al 2000) and have been shown to persist several hours after exercise (Ostrowski et al 1999). Third, albeit smaller in absolute values, a similar systemic inflammatory response has been described in healthy subjects after strenuous resistive breathing (at 75\% of their MIP) (Anzueto et al 1994; Bury et al 1996; Vassilakopoulos et al 1999). Finally, increased TNF $\alpha$ levels have been reported in COPD patients after moderate-intensity constant-work-rate exercise (Rabinovich et al 2003). To our knowledge, however, no previous study has investigated the effects of progressive inspiratory loading of the respiratory muscles upon systemic inflammation in patients with COPD.

At variance with our working hypothesis, we were not able to show that that MILT exerts a significant pro-inflammatory effect in patients with COPD. Several reasons can explain this observation. First, the peak inspiratory load achieved by our

Table 2 Maximal inspiratory loading test (MILT) results

\begin{tabular}{lll}
\hline & COPD patients & Healthy subjects \\
\hline Pmouth peak/MIP(\%) & $32.5 \pm 6.5$ & $29.9 \pm 4.2$ \\
Peak load $(\mathrm{gr})$ & $125.0 \pm 22.4^{* *}$ & $287.5 \pm 29.5$ \\
Duration (seconds) & $626 \pm 148$ & $654 \pm 69$ \\
$\mathrm{VO}_{2 \text { basal }}, \mathrm{L} \times \mathrm{min}^{-1}$ & $0.25 \pm 0.02$ & $0.28 \pm 0.0 \mathrm{I}$ \\
$\mathrm{VO}_{2 \text { max }}, \mathrm{L} \times \mathrm{min}^{-1}$ & $0.34 \pm 0.04^{\dagger}$ & $0.41 \pm 0.04^{\dagger}$ \\
$\mathrm{VCO}_{\text {basal }^{\dagger}} \mathrm{L} \times \mathrm{min}^{-1}$ & $0.22 \pm 0.01$ & $0.23 \pm 0.01$ \\
$\mathrm{VCO}_{2 \text { max }}, \mathrm{L} \times \mathrm{min}^{-1}$ & $0.25 \pm 0.03^{*+}$ & $0.34 \pm 0.04^{\dagger}$ \\
\hline
\end{tabular}

Abbreviations: Pmouth peak, peak mouth pressure, expressed as percentage of Maximal inspiratory pressure (MIP); $\mathrm{VO}_{2 \text { basal, }}$, basal oxygen consumption; $\mathrm{VO}_{2 \max }$ maximal oxygen consumption; $\mathrm{VCO}_{2 \text { basal, }}$, $\mathrm{CO}_{2}$ consumption.

${ }^{*} \mathrm{p}<0.05,{ }^{* *} \mathrm{p}<0.0$ I versus healthy subjects; ${ }^{\dagger} \mathrm{p}<0.05$ versus basal in the same group. 

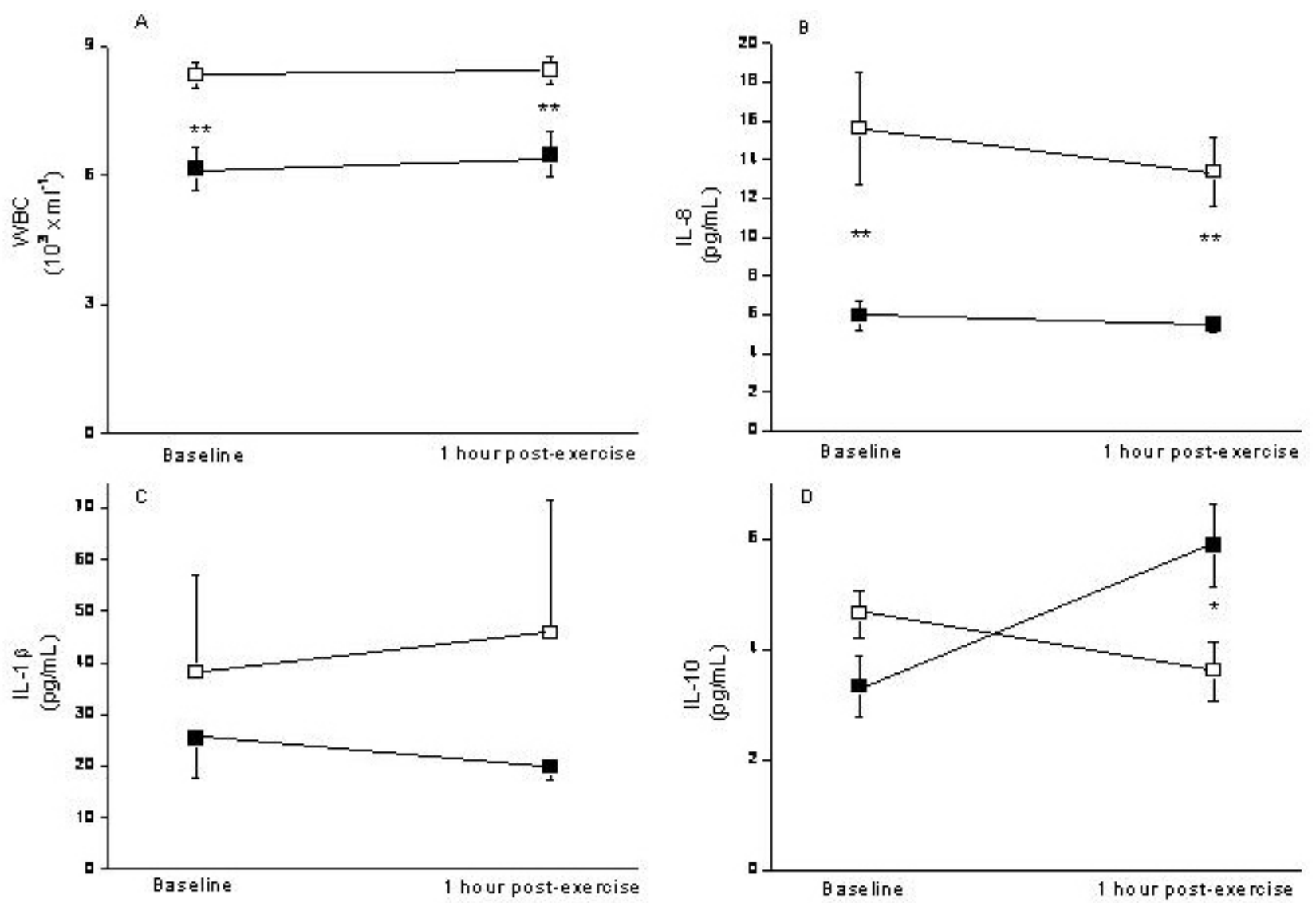

Figure I Systemic inflammatory markers determined in patients with COPD (open squares) and healthy controls (closed squares), before and after maximal incremental inspiratory loading.

$*_{p}<0.05, *_{p}<0.01$ versus controls.

patients averaged only about $30 \%$ of their MIP whereas those previous studies in healthy subjects reporting increased systemic inflammation after inspiratory loading achieved a peak inspiratory load of about $75 \%$ of their MIP (Vassilakopoulos et al 1999, 2002). It is possible, therefore, that a higher inspiratory load may have resulted indeed in systemic inflammation in our patients, as hypothesized. Yet, the severity of their airflow obstruction precluded them to achieve and sustain these high loads. Actually, Koechlin and colleagues (2004) also failed to induce systemic inflammation in patients with COPD after localized quadriceps exercise at $40 \%$ of its maximal strength. Second, blood samples were obtained 1 hour after MILT. It is therefore possible that earlier sampling may have picked up higher systemic cytokine concentrations. However, previous studies investigating whole body exercise found positive results within the time framework used in our study (Suzuki et al 1999). Finally, it is known that inhaled steroids can reduce systemic inflammation in COPD (Sin et al 2004). Given that all the patients studied here received them, we can not exclude that a different result may have been obtained should patients not under inhaled steroid therapy had been studied.
In contrast, we found that the anti-inflammatory cytokine IL-10 showed a different response to MILT in healthy subjects and in patients with COPD (Figure 1, panel D). IL-10 is a primary anti-inflammatory cytokine that acts by inhibiting pro-inflammatory cytokine production by activated monocytes and macrophages (Fiorentino et al 1991). Previous studies in healthy subjects have shown that plasma IL-10 increases significantly immediately after strenuous exercise (Suzuki et al 2000), fitting well with the period of resolution of the acute inflammatory response elicited by exercise (Ostrowski et al 1999; Smith et al 2000; Vassilakopoulos et al 2002). Also, these studies demonstrate that exercise induces a cascade of cytokine and the anti-inflammatory cytokine suggesting that there is a balance between pro-inflammatory and anti-inflammatory cytokines during and/or after exercise. In keeping with these observations, we found that IL-10 increased significantly after MILT in healthy subjects (Figure 1, panel D). In contrast, patients with COPD failed to do so. This may reflect a certain inability to restrict the magnitude and/or duration of the inflammatory response that may occur after exercise. 
It is interesting to note here that IL-10 has also been to be found reduced in the sputum of these patients (Takanashi et al 1999), which may contribute also to the maintenance of airway inflammation.

Two potential limitations of our study deserve comment. First, because this was a pilot physiological study, we did not formally calculated sample size. Instead, we evaluated a relatively small number of subjects, similarly to what other studies of this nature have done before (Takanashi et al 1999; Rabinovich et al 2003; Koechlin et al 2004). Second, controls were younger than patients. Some studies have suggested that ageing is associated with systemic inflammation (De Martinis et al 2006). Therefore, we can not exclude an independent effect of ageing.

In summary, the present study suggests that patients with severe COPD have systemic inflammation and shows that MILT in these patients fails to elicit a significant systemic inflammatory response. Yet, the capacity of these patients to mount an adequate anti-inflammatory response seems jeopardized. Whether this occurs also during other forms of respiratory loading (exercise during activities of daily living, acute exacerbation of COPD) requires further study.

\section{Disclosure}

Supported, in part, by ABEMAR. There is no conflict of interest.

\section{Acknowledgments}

The authors thank the participating individuals for their collaboration in the study, and M. Bosch RN, A. Noguera RN, M. López RN , M.J. Hernández RN and M.V.Ramis RN for their help during the study.

\section{References}

Agusti AG, Noguera A, Sauleda J, et al. 2003. Systemic effects of chronic obstructive pulmonary disease. Eur Respir J, 21:347-60.

American Thoracic Society. 1995. Official Statement. Standardization of Spirometry. 1994 Update. 1995. Am J Respir Crit Care Med, 152:1107-36.

Anzueto A, Supinski GS, Levine SM, et al. 1994. Mechanisms of disease: Are oxygen-derived free radicals involved in diaphragmatic dysfunction. Am J Respir Crit Care Med, 149:1048-52.

Barbera JA, Roca J, Ferrer A, et al. 1997. Mechanisms of worsening gas exchange during acute exacerbations of chronic obstructive pulmonary disease. Eur Respir J, 10:1285-91.

Bury TB, Louis R, Radermecker MF, et al. 1996. Blood mononuclear cells mobilization and cytokines secretion during prolonged exercises. Int J Sports Med, 17:156-60.

De Martinis M, Franceschi C, Monti D, et al. 2006. Inflammation markers predicting frailty and mortality in the elderly. Exp Mol Pathol, 80:219-27.

Fiorentino DF, Zlotnik A, Mosmann TR, et al. 1991. IL-10 inhibits cytokine production by activated macrophages. J Immunol, 147:3815-22.
Hogg JC. 2004. Pathophysiology of airflow limitation in chronic obstructive pulmonary disease. Lancet, 364:709-21.

Koechlin C, Couillard A, Cristol JP, et al. 2004. Does systemic inflammation trigger local exercise-induced oxidative stress in COPD? Eur Respir J, 23:538-44.

Malo O, Sauleda J, Busquets X, et al. 2002. Inflamación sistémica durante las agudizaciones de la enfermedad pulmonar obstructiva crónica. Arch Bronconeumol, 38:172-6.

Martyn JB, Moreno RH, Paré PD, et al. 1987. Measurement of inspiratory muscle performance with incremental threshold loading. Am Rev Respir Dis, 135:919-23.

Morales P, Sanchis J, Cordero PJ, et al. 1997. Maximum static respiratory pressures in adults. The reference values for a Mediterranean Caucasian population. Arch Bronconeumol, 33:213-19.

Ostrowski K, Rohde T, Asp S, et al. 1999. Pro- and anti-inflammatory cytokine balance in strenuous exercise in humans. J Physiol, 515:287-91.

Pauwels RA, Buist AS, Calverley PM, et al. 2001. Global strategy for the diagnosis, management, and prevention of chronic obstructive pulmonary disease. NHLBI/WHO Global Initiative for Chronic Obstructive Lung Disease (GOLD) Workshop summary. Am J Respir Crit Care Med, 163:1256-76.

Pizza FX, Mitchell JB, Davis BH, et al. 1995. Exercise-induced muscle damage: effect on circulating leukocyte and lymphocyte subsets. Med Sci Sports Exerc, 27:363-70.

Rabinovich RA, Figueras M, Ardite E, et al. 2003. Increased tumour necrosis factor-alpha plasma levels during moderate-intensity exercise in COPD patients. Eur Respir J, 21:789-94.

Ramirez-Sarmiento A, Orozco-Levi M, Guell R, et al. 2002. Inspiratory muscle training in patients with chronic obstructive pulmonary disease: structural adaptation and physiologic outcomes. Am J Respir Crit Care Med, 166:1491-97.

Roca J, Sanchis J, Agustí-Vidal A, et al. 1986. Spirometric reference values for a mediterranean population. Bull Eur Physiopathol Respir, 22: $217-24$.

Rohde T, MacLean DA, Richter EA, et al. 1997. Prolonged submaximal eccentric exercise is associated with increased levels of plasma IL-6. Am J Physiol, 273:E85-E91.

Sen CK. 1995. Oxidants and antioxidants in exercise. J Appl Physiol, 79: 675-86.

Sin DD, Lacy P, York E, et al. 2004. Effects of fluticasone on systemic markers of inflammation in chronic obstructive pulmonary disease. Am J Respir Crit Care Med, 170:760-65.

Smith LL, Anwar A, Fragen M, et al. 2000. Cytokines and cell adhesion molecules associated with high-intensity eccentric exercise. Eur J Appl Physiol, 82:61-7.

Suzuki K, Totsuka M, Nakaji S, et al. 1999. Endurance exercise causes interaction among stress hormones, cytokines, neutrophil dynamics, and muscle damage. $J$ Appl Physiol, 87:1360-7.

Suzuki K, Yamada M, Kurakake S, et al. 2000. Circulating cytokines and hormones with immunosuppressive but neutrophil-priming potentials rise after endurance exercise in humans. Eur J Appl Physiol, 81:281-7.

Takanashi S, Hasegawa Y, Kanehira Y et al. 1999. Interleukin-10 level in sputum is reduced in bronchial asthma, COPD and in smokers. Eur Respir J, 14:309-14.

Vassilakopoulos T, Zakynthinos S, Roussos C. 1999. Strenuous resistive breathing induces proinflammatory cytokines and stimulates the HPA axis in humans. Am J Physiol, 277: R1013-19.

Vassilakopoulos T, Katsaounou P, Karatza MH, et al. 2002. Strenuous resistive breathing induces plasma cytokines: role of antioxidants and monocytes. Am J Respir Crit Care Med, 166:1572-8.

Vassilakopoulos T, Roussos C, Zakynthinos S. 2004. The immune response to resistive breathing. Eur Respir J, 24:1033-43. 
